Original Article

\title{
DEGRADATION KINETICS OF CARVEDILOL PHARMACEUTICAL DOSAGE FORMS (TABLETS) THROUGH STRESS DEGRADATION STUDY
}

\author{
NITIN MAHAJAN ${ }^{*}$, SUPARNA DESHMUKH ${ }^{2}$, MAZAHAR FAROOQUI ${ }^{1}$
}

1Post Graduate and Research Centre, Department of Chemistry, Maulana Azad College of Arts, Science and Commerce, Dr. Babasaheb Ambedkar Marathwada University, Aurangabad, Maharashtra, 431001, India, 2Department of Chemistry, S. K. Gandhi College, Kada, Tal: Asthi, Dist: Beed, Maharashtra, 414202, India

Email: mahajan1925@gmail.com

Received: 12 Sep 2021, Revised and Accepted: 15 Nov 2021

\section{ABSTRACT}

Objective: The aim of the research work to monitor impurities profiling and degradation kinetics of Carvedilol Pharmaceutical Dosage Form (Tablets) through stress degradation study.

Methods: To study impurity profiling and degradation kinetics Chromatographic condition used as, Inertsil ODS 3V column (150 mm x 4.6 mm, $5 \mu \mathrm{m}$ ) with mobile phase consisting Mobile phase-A (Water, Acetonitrile and Trifluroacetic acid in the ratio of 80:20:0.1 v/v/v respectively and pH adjusted to 2.0 with dilute potassium hydroxide solution) and Mobile phase-B (Water and acetonitrile in the ratio of $100: 900 \mathrm{v} / \mathrm{v}$ respectively) delivered at flow rate of $1.0 \mathrm{ml} \mathrm{min}{ }^{-1}$ and the detection wavelength $240 \mathrm{~nm}$. The column compartment temperature maintained at $40{ }^{\circ} \mathrm{C}$.

Results: Stress degradation study conducted using Acid, Alkali, Oxidation, Humidity, Thermal and Photolytic stress degradation conditions. Known, unknown and degradant impurities nature and degradation kinetics in different stressed degradation conditions were monitored through stability indicated method reverse phase HPLC method. Carvedilol molecule found sensitive to Oxidation and Alkali conditions. Impurity-A significantly increased from its not detected level.

Carvedilol molecule found stable in Acid, Humidity, Thermal and Photolytic stress degradation condition. In all stressed conditions, mass balance was found between $95 \%$ to $105 \%$ and peak purity of carvedilol peak was found pure.

Conclusion: Stress degradation study is required to know the degradation pathway of product and to prove the stability indicating nature of the analytical method. Study provide information pertaining to the intrinsic stability of drug product.

Keywords: Carvedilol tablets, Impurities profiling, Forced degradation study, Stress study

(C) 2022 The Authors. Published by Innovare Academic Sciences Pvt Ltd. This is an open access article under the CC BY license (https://creativecommons.org/licenses/by/4.0/) DOI: https://dx.doi.org/10.22159/ijcpr.2022v14i1.44112 Journal homepage: https://innovareacademics.in/journals/index.php/ijcpr

\section{INTRODUCTION}

Carvedilol chemically it is named, $( \pm)-1$-(carbazol-4-yloxy)-3-((2-omethoxyphenoxy) ethyl) amino)-2-propanol. Carvedilol is a racemic mixture where the $S(-)$ enantiomer is a beta-adrenoceptor blocker and the $\mathrm{R} \mathrm{(+)} \mathrm{enantiomer} \mathrm{is} \mathrm{both} \mathrm{a} \mathrm{beta} \mathrm{and} \mathrm{alpha-} 1$ adrenoceptor blocker and is currently used to treat heart failure, left ventricular dysfunction and hypertension $[1,2]$. Carvedilol shows greater antioxidant activity than other commonly used beta-blockers $[3,4]$. It has been prescribed as an antihypertensive agent, an antiangina agent [5-8]. The dual action of carvedilol is advantageous in combination therapies as moderate doses of 2 drugs have a decreased incidence of adverse effects compared to high dose monotherapy in the treatment of moderate hypertension [9]. Stress degradation indicates the chemical behaviour of the molecule, which give the necessary information in development of pharmaceutical dose.

As per guidance given by International Conference on Harmonization (ICH) guidelines (Q1A), Stability studies of pharmaceutical dose needs to be performed to decide to propose shelf life of drug product [10]. Stability study of drug substance and drug product provide vital information pertaining to the intrinsic stability of the molecule. During stability/stress forced degradation study drug substance/drug product will degrade or decompose and will produce other related substance, which is known as impurities/degradants. These impurities then monitored through suitable stability-indicating method in which these impurities are well separated from each other and from the main drug component. Hence stress degradation study is a tool to identify and estimate the degradants impurities that would occur during the stability study of drug product. Stress degradation study of drug substance/drug product provide the following important information.

a) Determine the route of degradation of drug substance and drug product.

b) Differentiate the degradation product which is generating from drug substance and with excipient interaction with drug substance in drug product.

c) Help in the determination of structure of degradation product.

d) To show the degradation mechanism such as hydrolysis, oxidation, thermolysis or photolysis of the drug substance and drug product [11].

e) Help in the determination of the stability-indicating nature of the method.

f) To understand the chemical nature of the drug molecule.

g) To get the possible information degradant in stability study of drug product [12].

The extensive literature review found that several RP-HPLC method reported for the determination of assay of Carvedilol alone [13-22] and with combination of other drugs [23-25] and very few methods have been reported to determine related substances [26-28]. None of the methods discussed pertaining to degradation kinetic of known and unknown impurities.

The chemical name of Carvedilol are shown in table 1 and its structure shown in fig. 1 
Table 1: Chemical name of carvedilol

\begin{tabular}{ll}
\hline Compound name & Chemical name \\
\hline Carvedilol & $( \pm)-1-($ Carbazol-4-yloxy)-3-[\{2-(0-methoxyphenoxy) ethyl $\}$ amino]-2-propanol \\
\hline
\end{tabular}

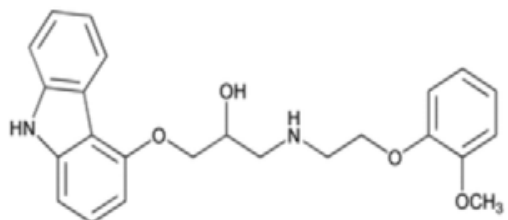

Fig. 1: Carvedilol

\section{MATERIALS AND METHODS}

\section{Regents and materials}

Marketed samples of Carvedilol tablets were used for degradation kinetic of carvedilol. Its associated related substances (impurities) were obtained from OLYMPUS Chemical and Fertilizers from Mumbai, India. Trifluroacetic acid and Acetonitrile were procured from spectrochemLimited, HPLC grade water was obtained from Milli-Q purification system. $0.45 \mu \mathrm{m}$ PVDF filter used of Merck India make.

\begin{abstract}
Instrumentation
HPLC (Make: Waters) equipped with an integrated autosampler and a quaternary gradient pump was used. The column holder having temperature controlled and an Ultraviolet (UV)/Photodiode array detector (PDA) was used for the development and analytical method validation. Chromatographic data was acquired using empower software.
\end{abstract}

\section{Chromatographic conditions}

Inertsil ODS3V $(150 \times 4.6) \mathrm{mm}, 5 \mu \mathrm{m}$ column was used. The column holder temperature maintained at $40{ }^{\circ} \mathrm{C}$. The mobile phase consist of a different composition of buffer solution and organic solvents. Mobile Phase-A is mixture of Water, Acetonitrile and Trifluroacetic acid in the ratio $80: 20: 0.1 \mathrm{v} / \mathrm{v} / \mathrm{v}$ and $\mathrm{pH}$ of this mixture adjusted to 2.0 with dilute potassium hydroxide solution.

Mobile Phase-B is mixture water and Acetonitrile in the ratio 10:90 $\mathrm{v} / \mathrm{v}$.

HPLC gradient programme run mentioned in table 2.

Table 2: Mobile phase programme for gradient elution

\begin{tabular}{llll}
\hline Time (min) & Flow (ml/min) & Mobile phase-A (\%) & Mobile phase-B (\%) \\
\hline 0 & 1.0 & 80 & 20 \\
10 & 1.0 & 80 & 20 \\
30 & 1.0 & 60 & 40 \\
40 & 1.0 & 60 & 40 \\
50 & 1.0 & 80 & 20 \\
60 & 1.0 & 80 & 20 \\
\hline
\end{tabular}

\section{Diluent}

Mixture of $0.02 \mathrm{M} \mathrm{KH}_{2} \mathrm{O}_{4}$ buffer $\mathrm{pH} 2.5$ and Acetonitrile in the ratio $65: 35 \mathrm{v} / \mathrm{v}$

\section{Standard solution preparations}

Solution containing $2 \mu \mathrm{g} / \mathrm{ml}$ of Carvedilolstandard prepared in diluent.

\section{Controlled sample solution}

Accurately weigh and transferred tablets powder equivalent to 25 $\mathrm{mg}$ of Carvedilol into $25 \mathrm{ml}$ volumetric flask, Add about $20 \mathrm{ml}$ of diluent sonicated for 30 min with intermittent shaking and make the volume with diluent. Filtered through $0.45 \mu \mathrm{m}$ PVDF filter after discarding first five $\mathrm{ml}$ of filtrate. (Sample concentration: $1000 \mu \mathrm{g} / \mathrm{ml}$ )

\section{Sample preparation for force degradation study}

Different degradation samples were prepared as mentioned below (table 3). They were analysed along with a controlled sample (nonstressed sample). \%Degradation was calculated in terms of \% total impurities (known and unknown impurities) along with Mass Balance.

Table 3: Degradation study data for carvedilol tablets

\begin{tabular}{|c|c|c|c|c|c|c|}
\hline Stress condition & $\begin{array}{l}\% \text { Total } \\
\text { impurity }\end{array}$ & $\begin{array}{l}\text { \% Assay of } \\
\text { carvedilol }\end{array}$ & $\begin{array}{l}\text { \% Mass } \\
\text { balance }\end{array}$ & $\begin{array}{l}\text { Purity } \\
\text { angle }\end{array}$ & Purity threshold & $\begin{array}{l}\text { Purity } \\
\text { flag }\end{array}$ \\
\hline $1 \mathrm{~N} \mathrm{HCl} / 70^{\circ} \mathrm{C}$ in water bath for $5 \mathrm{~h}$ & 0.31 & 99.5 & 99.8 & 0.032 & 0.267 & No \\
\hline $1 \mathrm{~N} \mathrm{NaOH} / 70{ }^{\circ} \mathrm{C}$ in water bath for $2 \mathrm{~h}$ & 2.69 & 99.8 & 102.5 & 0.030 & 0.265 & No \\
\hline $5 \% \mathrm{H}_{2} \mathrm{O}_{2}$ for $72 \mathrm{~h}$ at room temperature. & 5.34 & 93.5 & 98.8 & 0.032 & 0.269 & No \\
\hline Humidity $/\left(40{ }^{\circ} \mathrm{C} / 75 \% \mathrm{RH}\right)$ for $5 \mathrm{~d}$ & 0.22 & 99.7 & 99.9 & 0.032 & 0.273 & No \\
\hline Thermal $/ 80^{\circ} \mathrm{C} / 48 \mathrm{~h}$ & 0.28 & 99.1 & 99.4 & 0.035 & 0.272 & No \\
\hline Photolytic/250 Wh/m2 & 0.14 & 99.7 & 99.8 & 0.035 & 0.272 & No \\
\hline
\end{tabular}

\section{Acid degradation}

Solution containing $1000 \mathrm{mg} / \mathrm{ml}$ of Carvedilol was treated with $1 \mathrm{~N}$ hydrochloric acid $(\mathrm{HCl})$. This solution are subjected to the condition mentioned in table 3 .

This solution was neutralized with $1 \mathrm{~N}$ sodium hydroxide $(\mathrm{NaOH})$.

\section{Base degradation}

Solution containing $1000 \mu \mathrm{g} / \mathrm{ml}$ of Carvedilolwas treated with $1 \mathrm{~N}$ sodium hydroxide $(\mathrm{NaOH})$. The degradation condition mentioned in table 3.
This solution was neutralized with $1 \mathrm{~N}$ hydrochloric acid (HCI).

\section{Oxidative condition}

Solution containing $1000 \mu \mathrm{g} / \mathrm{ml}$ of Carvedilolwas treated with $5 \%$ $\mathrm{v} / \mathrm{v}$ hydrogen peroxide $\left(\mathrm{H}_{2} \mathrm{O}_{2}\right)$. The degradation condition mentioned in table 3 .

\section{Thermal degradation study}

Transferred tablets powder equivalent to $25 \mathrm{mg}$ of Carvedilol into dry $25 \mathrm{ml}$ volumetric flask and kept in oven, the degradation conditions mentioned in table 3. 


\section{Photolytic degradation study}

Transferred tablets powder equivalent to $25 \mathrm{mg}$ of Carvedilol into dry $25 \mathrm{ml}$ volumetric flask and exposed light providing anoveral illumination of not less than 1.2 million lux hours and ultraviolet energy of not less than $200 \mathrm{Wh} / \mathrm{m} 2$ asperphoto stability testing guideline [29].

\section{RESULTS AND DISCUSSION}

Carvedilol molecule can be synthesized in many routes one of them is mentioned below [30]

Other synthetic route to synthesize Carvedilol molecule is mentioned below.

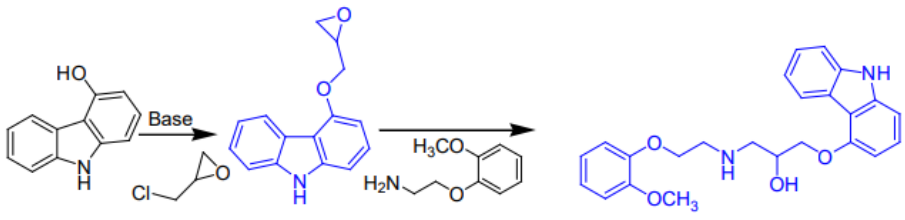

Fig. 2: Synthesis route-1
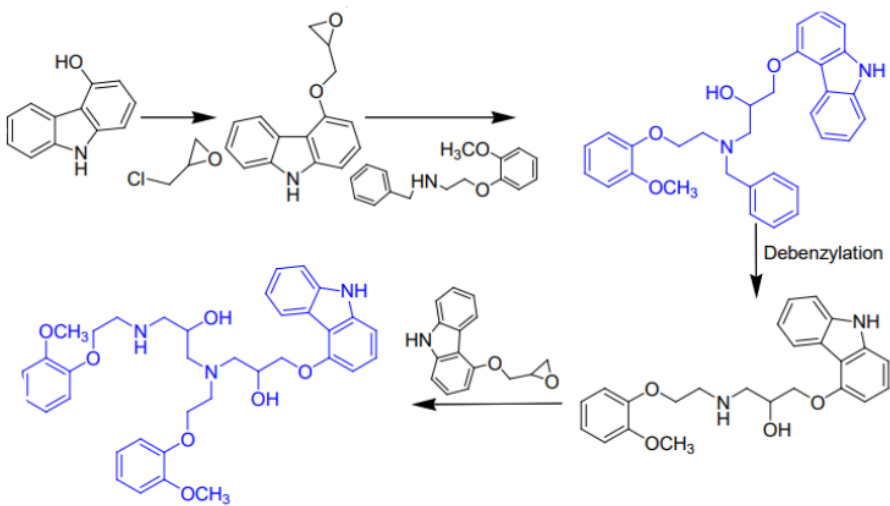

Fig. 3: Synthesis route-2

Impurities in pharmaceuticals are the unwanted chemical that remain with the active pharmaceutical ingredients (APIs), or develop during formulation or upon aging of the both API and formulated APIs to medicines. The presence of these unwanted chemicals, even in small amounts, many influences the efficacy and safety of the pharmaceutical products. Impurity profiling (i.e. the identity as well as the quantity in the pharmaceuticals) is one of the most important aspect of quality of drug product.
During synthesis of carvedilol molecule by different rout yields many impurities. There are possibility of generation of many impurities, which are process-related and degradants impurities depending on process route, which is also mention in European and US pharmacopeia. The possible generation of impurities are mentioned below.

The chemical name of carvedilol impurities are shown in table 4.

Table 4: Chemical name of carvedilol impurities

\begin{tabular}{|c|c|c|}
\hline Compound name & Chemical name & Molecular weight \\
\hline Carvedilol EP Impurity-A & $\begin{array}{l}\text { 1-(4-(2-Hydroxy-3-(2-(2-methoxyphenoxy) ethylamino) propoxy)-9H-carbazol-9-yl)-3-(2- } \\
\text { (2-methoxyphenoxy) ethylamino) propan-2-ol }\end{array}$ & 629.74 \\
\hline Carvedilol EP Impurity-B & 3,3'-(2-(2-Methoxyphenoxy)ethylazanediyl)bis(1-(9H-carbazol-4-yloxy) propan-2-ol) & 645.74 \\
\hline Carvedilol EP Impurity-C & 1-(9H-Carbazol-4-yloxy)-3-(benzyl(2-(2-methoxyphenoxy)ethyl) amino)propan-2-ol & 496.6 \\
\hline Carvedilol EP Impurity-D & $\begin{array}{l}\text { 1-(9H-Carbazol-4-yloxy)-3-[4-[2-hydroxy-3-[[2-(2-methoxyphenoxy)ethyl]amino]propoxy] } \\
\text { 9H-carbazol-9-yl] propan-2-ol }\end{array}$ & 645.76 \\
\hline
\end{tabular}

The structure of Carvedilol impurities are shown in fig. 4, fig. 5, fig. 6 and fig. 7

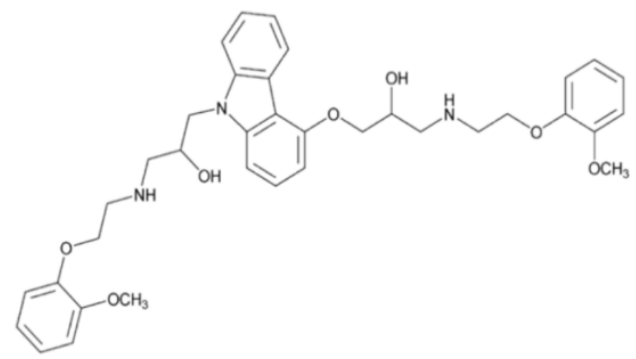

Fig. 4: Carvedilol EP Impurity-A

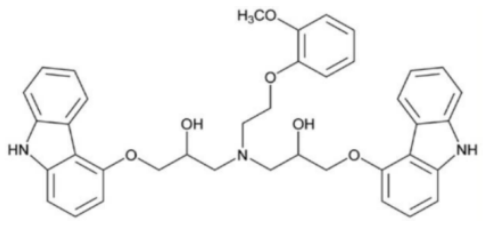

Fig. 5: Carvedilol EP Impurity-B

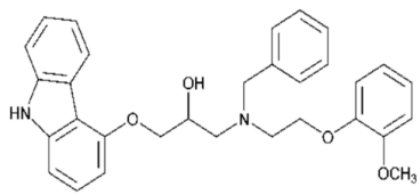

Fig. 6: Carvedilol EP Impurity-C 


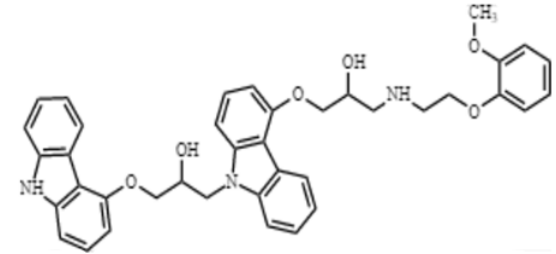

Fig. 7: Carvedilol EP Impurity-D
Force degradation samples were analysed with a stability indicating method using PDA detector [31,32]. Peak purity results (purity angle<purity threshold) for anlaytes indicates the homogeneity and purity of Carvedilol peak and its related impurities. There is no interference observed for analyte peak and its known impurities form blank and placebo, proving the specificity of the method.

The fig. 8, fig. 9 and fig. 10 shows representative chromatograms of Blank, Placebo and spiked sample (with all known impurities).

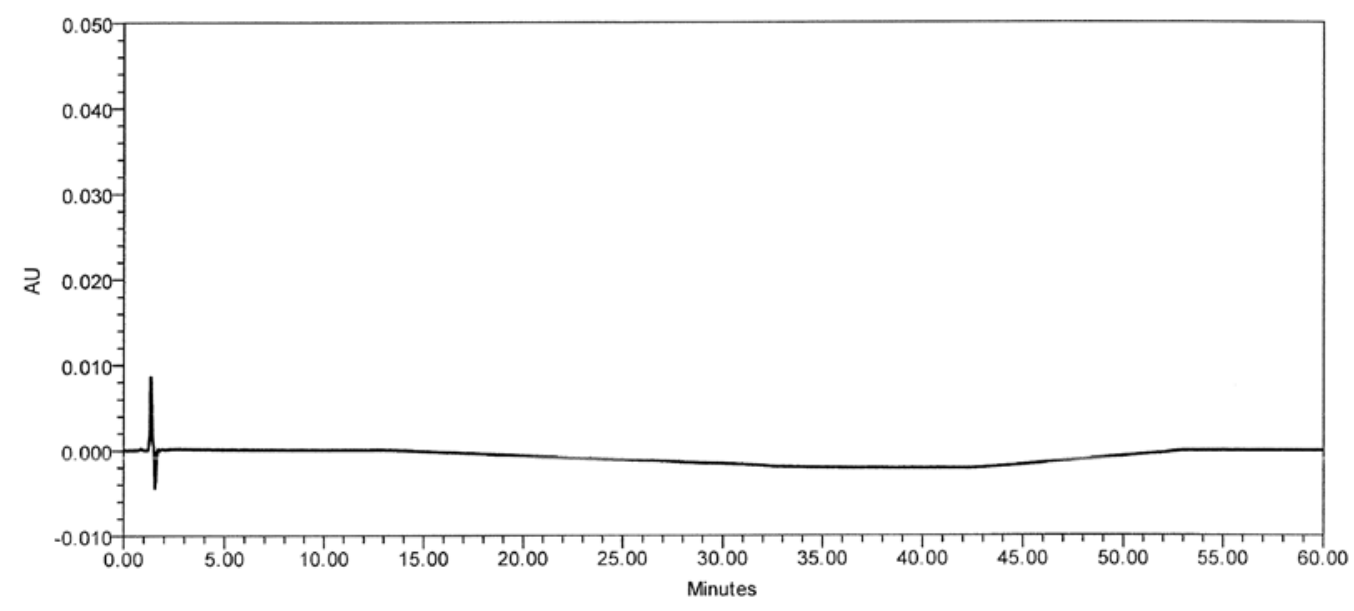

Fig. 8: Typical HPLC chromatogram of blank

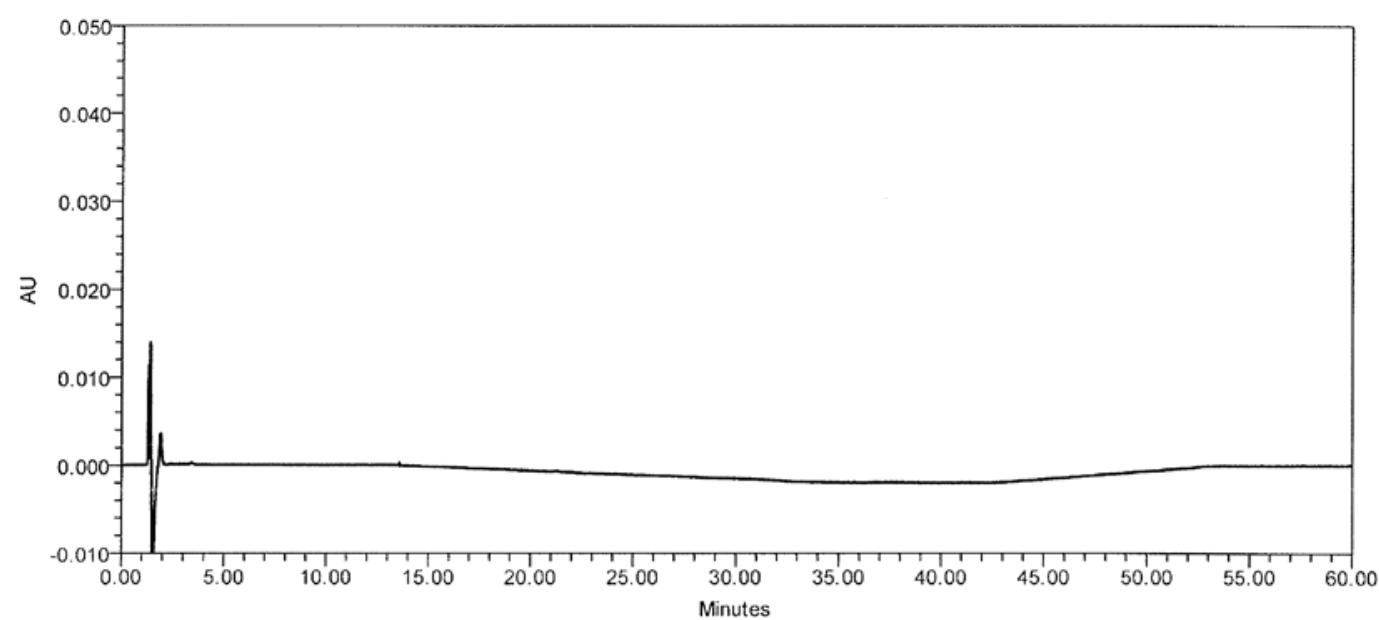

Fig. 9: Typical HPLC chromatogram of placebo solution

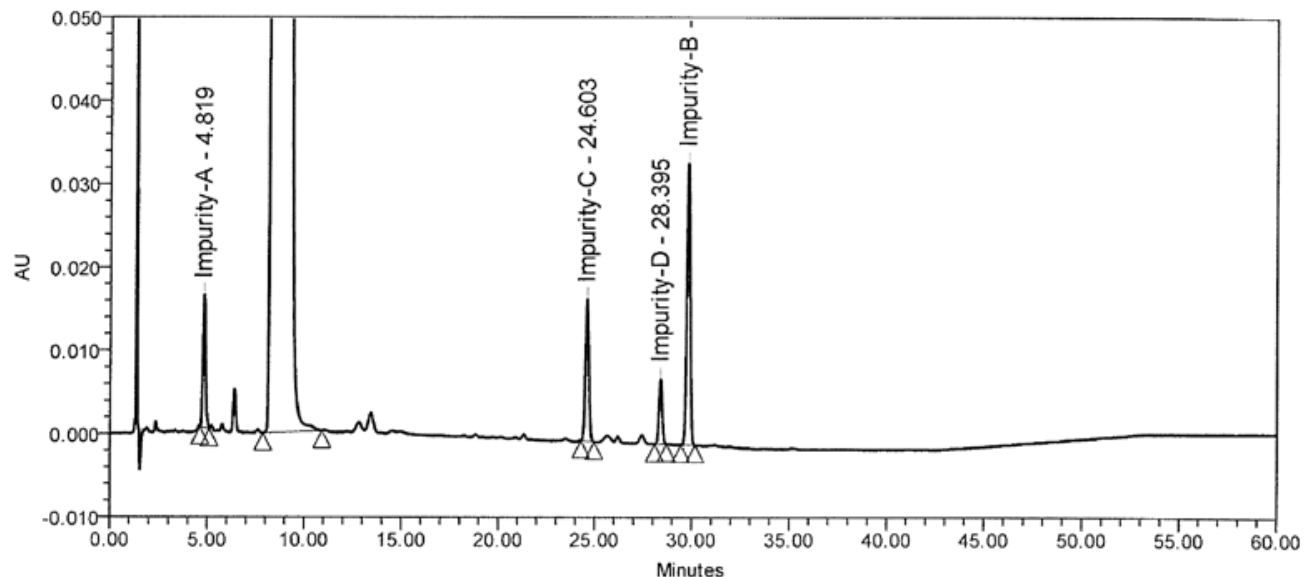

Fig. 10: Typical HPLC chromatogram of spike sample 
The Force degradation study (stress study) revealed that all the peaks i.e. Carvedilol peak, known impurities, unknown impurities and degradants, are well resolved from each other which is visiblyconfirmedin fig. 11 and fig. 12.

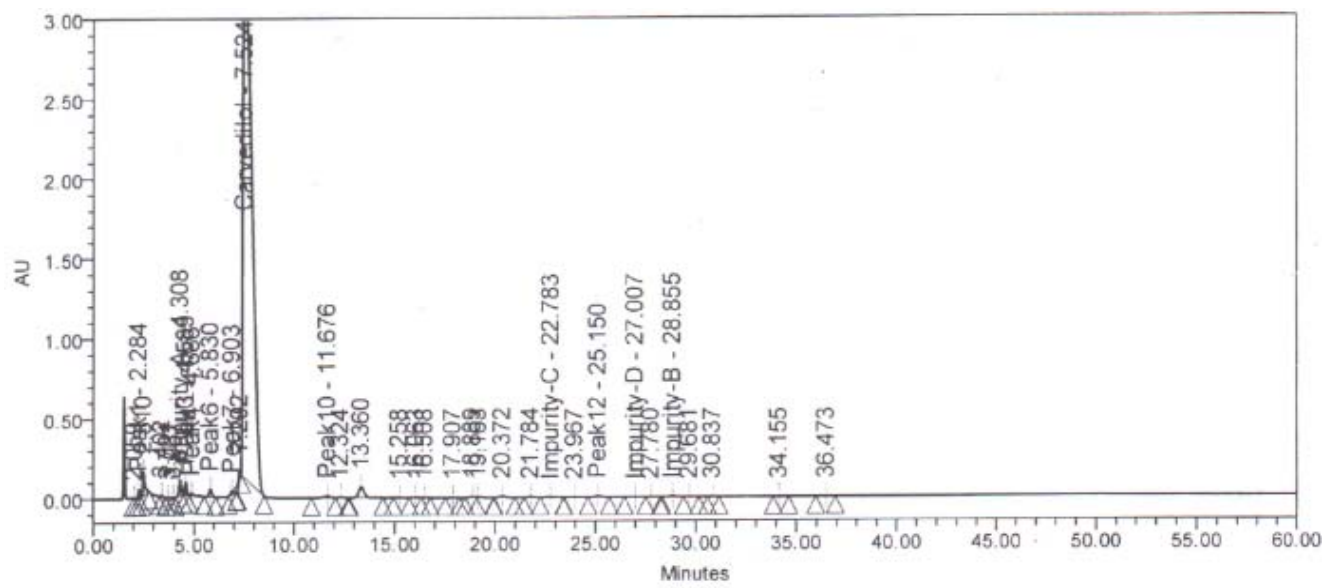

Fig. 11: Typical HPLC chromatogram of oxidation degradation

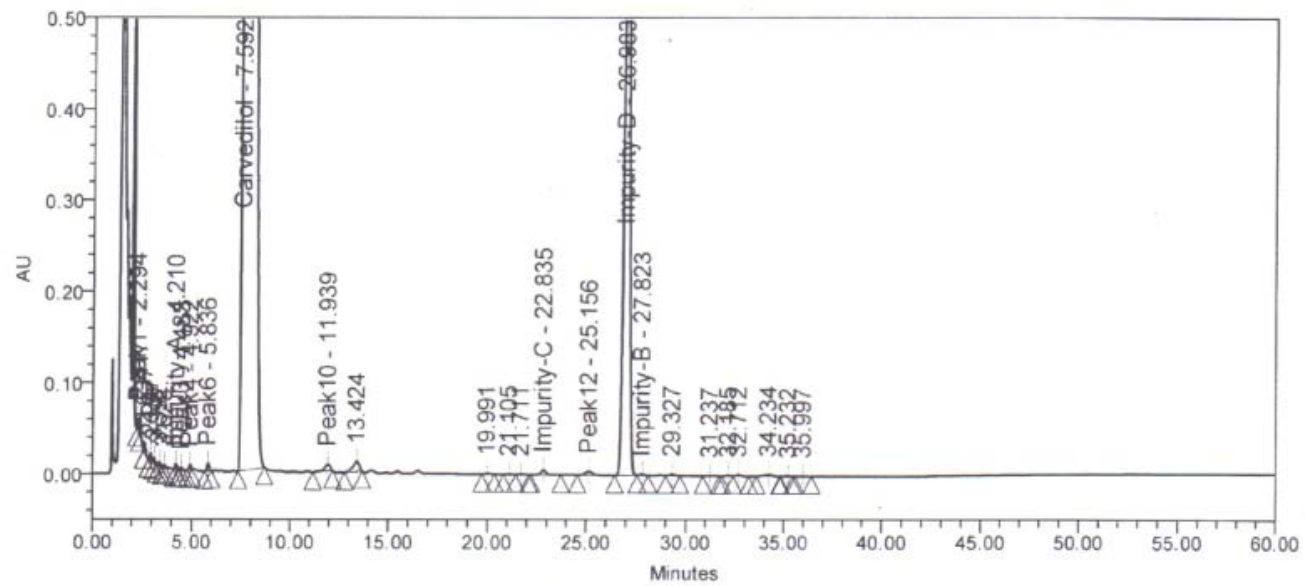

Fig. 12: Typical HPLC chromatogram of Alkali degradation

Carvedilol can easily oxidised and form biproduct and this biproduct is Carvedilol impurity-A which increases in presence of oxygen. In fig. 11 it was observed that in oxidation treated sample known Impurity-A, unknown impurity at 1.78 RRT and in fig. 12 Alkali treatment sample known Impurity-D, unknown impurity at 1.78 RRT was formed as a major degradation impurity. In Acid, Humidity, Thermal and Photolytic conditions drug product found stable.

The \% degradation with acceptable mass balance of Force degradation study (stress study) results reported in table 4.

\section{CONCLUSION}

Stress degradation studies provide vital information in developing new drug molecule or drug product. It give the necessary information of degradation pathway of the molecule which will play very important role in stability of drug product. In Drug product development by different synthetic route of API (Active Pharmaceutical Ingredient) was used; hence it is important to perform the stress degradation study to know different impurities profiling of known and unknown impurities. The degradants which is formed during stress degradation studies can be identified their structure which will give the information pertaining to toxic nature of degradants and can be controlled during the drug development stage. Stress degradation study also helps in deciding the manufacturing process, optimization of process parameter in different stages of drug product production, packaging condition, packaging material of drug product.

\section{ACKNOWLEDGMENT}

The author wishes thanks to management of Maulana Azad College of Arts, Science and Commerce for providing excellent research facilities.

\section{FUNDING}

Nil

\section{AUTHORS CONTRIBUTIONS}

All the authors have contributed equally.

\section{CONFLICT OF INTERESTS}

Declared none

\section{REFERNCES}

1. FDA Approved Drug Products: Carvedilol Oral Tablets. Available from: https://www.accessdata.fda.gov/drugsatfda_docs/label/2017/ 020297s038lbl.pdf. [Last accessed on 25 Aug 2021]

2. FDA Approved Drug Products: Carvedilol Oral ExtendedRelease Capsules. Available from: https://www.accessdata.fda.gov/drugsatfda_docs/label/2017/ 022012s022lbl.pdf. [Last accessed on 25 Aug 2021]

3. Nakamura K, Kusano K, Nakamura Y, Kakishita M, Ohta K, Nagase S, Yamamoto M, Miyaji K, Saito H, Morita H, Emori T, Matsubara H, Toyokuni S, Ohe T. Carvedilol decreases elevated 
oxidative stress in human failing myocardium. Circulation. 2002;105(24):2867-71.

doi: 10.1161/01.cir.0000018605.14470.dd, PMID 12070115

4. Kukin ML, Kalman J, Charney RH, Levy DK, Buchholz Varley C, Ocampo ON, Eng C. Prospective, randomized comparison of effect of long-term treatment with metoprolol or carvedilol on symptoms, exercise, ejection fraction, and oxidative stress in heart failure. Circulation. 1999;99(20):2645-51. doi: 10.1161/01.cir.99.20.2645, PMID 10338457.

5. Varin F, Cubeddu LX, Powell JR. Liquid chromatographic assay and disposition of carvedilol in healthy volunteers. J Pharm Sci. 1986;75(12):1195-7. doi: 10.1002/jps.2600751218, PMID 3559930 .

6. Vander off BT, Ruppel H, Amsterdam PB. Carvedilol: the new role of beta-blockers in congestive heart failure. Am Fam Phys. 1998;58:1627-34.

7. Nichols AJ, Gellai M, Ruffolo RR. Studies on the mechanism of arterial vasodilation produced by the novel antihypertensive agent, carvedilol. Fundam Clin Pharmacol. 1991;5(1):25-38. doi: 10.1111/j.1472-8206.1991.tb00698.x, PMID 1712335.

8. Ruffolo RR, Gellai M, Hieble JP, Willette RN, Nichols AJ. The pharmacology of carvedilol. Eur J Clin Pharmacol. 1990;38;Suppl 2:S82-8. doi: 10.1007/BF01409471, PMID 1974511.

9. Morgan T. Clinical pharmacokinetics and pharmacodynamics of carvedilol. Clin Pharmacokinet. 1994;26(5):335-46. doi: 10.2165/00003088-199426050-00002, PMID 7914479.

10. International Conference on Harmonization (ICH) Q1A (R2): Stability testing of new drug substance and products. 4th version. February: Step Publishing; 2003.

11. Reynold DW, Alsante KM, Kevin L, Facchine KL, Mullaney JF, Motto MG. Available guidance and best practices for conducting forced degradation studies. Pharm Technol. 2002;26(2):48-56.

12. Brummer H. How to approach a forced degradation study. Life Sci Technol Bull. 2011;31:1-4.

13. Abdullah JW, Shariq H, Siddiqui JA. Method development and analytical method validation of carvedilol by high-performance liquid chromatography. J Pharmacyand Biol Sci (IOSR-JPBS). 2016;11:93-7.

14. Ciobanu AM, Pop A, Crisan S, Pali M, Burcea Drag G, Popa D. HPLC studies for assessing the stability of carvedilol tablets. Farmacia. 2017;65:523.

15. Savic I, Marinkovc V, Sibinovic P, Cekic N. Application of the experimental design method to photostability studies of Karvileks tablet. Indian J Pharm Educ Res. 2012;43:275-82.

16. Sripalakit P, Kaewnok S, Tubtonglang S. Development of carvedilol assay in tablet dosage form using HPLC with fluorescence detection. Maejo Int J Sci Technol. 2010;4:8-19.

17. Mahaveer S, Kashkhedikar SG, Love S, Garg A, Tripti G, Patel A. Development of RP-HPLC method for estimation of carvedilol in tablet formulations. Res J Pharm Technol. 2008;1:18-21.
18. Uma V, Rao M, Haritha G, Krishnaiah T, Gouri T, Saikiran Method development and forced degradation studies of carvedilol by RP-HPLC. Int J Pharm Anal Res. 2017;6:457.

19. Desai DC, Karkhanis VV. Simple spectrometric estimation of carvedilol phosphate in bulk and tablet dosage form. Int Res J Pharm. 2012;3:114

20. Dey S, Kumar D, Sreenivas SA, Sandeep D. Analytical method development and validation of carvedilol by HPLC in bulk and dosage form. J Pharm Res. 2010;3:3075.

21. Suhagia LJ, Suhagia BN LJ, Shah PB, Shah RR. RP-HPLC and HPTLC methods for the estimation of carvedilol in bulk drug and pharmaceutical formulations. Ind J Pharm Sci. 2006;68(6):790-93.

22. Myung SW, Jo CH. Gas chromatograph-mass spectrometric method for the determination of carvedilol and its metabolites in human urine. J Chromatogr B Anal Technol Biomed Life Sci. 2005;822(12):70-7. doi: 10.1016/j.jchromb.2005.05.023, PMID 15996536.

23. Nadella NP, Ratnakaram VN, Srinivasu N. Development and validation of UPLC method for simultaneous quantification of carvedilol and ivabradine in the presence of degradation products using DoE concept. J Liq Chromatogr Relat Technol. 2018;41(3):143-53. doi: 10.1080/10826076.2018.1427595.

24. Mali AD. Simultaneous determination of carvedilol and hydrochlothiazide in pharmaceutical dosage form by firstorder derivative UV spectrophotometry. Int J Pharm Sci. 2015;7:371.

25. Sajan PG, Rohitha T, Patil P, Mantelingu K, Rangappa KS, Kumar MN. Rapid highly efficient and stability-indicating RP-HPLC method for the quantitative determination of potential impurities of carvedilol active pharmaceutical ingredient. Int J Pharm Pharm Sci. 2014;6:214.

26. Stojanovic J, Marinkovic V, Vladimirov S, Velickovic D, Sibinovic P. Determination of carvedilol and its impurities in pharmaceuticals. Chromatographia. 2005;62(9-10):539-42. doi: 10.1365/s10337-005-0656-y.

27. Kang TC GU, Xiao HE, Jia-jia. Determination of impurities $D$ and $E$ of carvedilol tablets by RP-HPL. Chin J Pharm Anal. 2015;35:1838.

28. Raju TVR. Development and validation of stability-indicating impurity profiling method for the carvedilol in API and pharmaceutical formulation. Int J Pharmacol Pharm Sciences. 2015;2:22.

29. International Conference on Harmonization (ICH) Q1B, Stability testing. USA: Photostability Testing of New Drug Substances and Products; 1996.

30. Modi IA, Patel SL, Muktawat S, Chandrasekaran R, Ponnaih R, Khamar BM. Process for the preparation of carvedilol via silyl protection of substituted amine. World Intellect Property Organ Wo; 2009. PMID 115902.

31. Marc V, Gorenstein, Li AV, Chapman JB. Detecting coeluted impurities by spectral comparison. Waters 199;12(10):768-72.

32. Young PM, Gorenstein MV. Tryptic mapping by reversed-phase HPLC with photodiode Arraydetection incorporating the spectral contrast technique. Elsevier NY. 1994;12(11):832-8. 